THE additions to the Zoological Society's Gardens during the past week include a Lesser White-nosed Monkey (Cercopithecus petaurista) from West Africa, presented by Mr. Robt. F. Clothier; two Ring-tailed Lemurs (Lemur catta) from Mada. gascar, presented by Mr. Hugh McCubbin; a European Bearded Vulture (Gypaetus barbatzss) from Southern Spain, presented by Lord Lilford, F.Z.S.; three Globose Curassows (Crax globicera) from Central America, presented by Major F. Hime ; a Lesser Sulphur-crested Cockatoo (Cacatua tenuirostris) from Moluccas, presented by Miss Langley; a White-tailed Gnu (Catoblepas gnul) from South Africa, two Mule Deer (Cervus macrotis) from North America, a Common Ocelot (Felis pardalis), a Red and Yellow Macaw (Ara chloroptera) from South America, deposited; a Funereal Cockatoo (Calyptorhynchus funereus) from New South Wales, four Common Crowned Pigeons (Gourd coronata) from New Guinea, two Yellow-bellied Parrakeets (Platycercus faviventris) from Tasmania, an American Kestrel (Tïnnunculus sparverius) from South America, a Smooth Snake (Coronella lavis) from Hampshire, purchased.

\section{ON TWO METEORS OBSERVED IN SWEDEN IN $1877^{1}$}

THE first meteor was observed over a great part of the middle of Sweden from Stockholm, in the east, to Charlottenberg (and Christiania), in the west, and from the neighbourhood of Areskutan, in the north, to Jönköping, in the south. Accounts of the phenomenon by forty-seven different observers are given. By a comparison of a number of those observations it appears that the meteor was seen nearly simultaneously over the whole of the area where it was visible, on March 18 , at $7 \mathrm{~h}$. $52.5 \mathrm{~m}$. P.M. Greenwich mean time. The phenomenon lasted only a few seconds.

When lines, showing the direction in which the meteor was seen from every separate point of observation to sink under the horizon or in which the last explosion took place, are drawn on the map, most of them meet on the Lake Vener, in the region of Vermlands Näs. The terminal point of the meteor's path was thus clearly situated above this region. Observations from Stockholm, that the meteor disappeared ...bout half way be. tween the moon and the horizon, and from Örebro that it split into fragments by the side of the moon, show that the last explosion took place at a height of 37 to 38 kilometres. Observa. tions from Carlstad and Edsvalla, that the meteor passed through the zenith, and from Mora, that its path was vertical, indicate a projection of its path over Mora and Carlstad, to Vermlands Näs. At first its inclination appears to have been only about $30^{\circ}$, but afterwards it became considerably greater. Besides the final explosion there were three other points of the meteor's path at which it threw out sparks, the first at a very considerable height-over 200 kilometres, the second at a height of ICO to I 50 kilometres. These figures, for which, however, no great degree of accuracy can be claimed, are deduced from an observation made in the neighbourhood of Orebro. That the continuation of the meteor's path could not be observed from this point was probably caused by the masses of dense cloud which the meteor heaped before it in its path, and which, in the neighbourhood of the place where it fell, almost completely concealed it from view.

As is commonly the case with meteor detonations in general, the sound was propagated with excessive irregularity, violent explosions having been heard in some places, while in others close by the whole phenomenon appeared to proceed without sound.

The circumstance that in the region of Vermlands Näs, at Edsvalla, Carlstad, Kinnekulle, and other places over which the meteor sprang asunder for the last time, no proper fireball was visible, but only a thrice-repeated lightning-like flash, shows that here, too, a part of the meteor's light was intercepted by the dense, cloudy masses which the meteor drove before it. A remarkable observation was made at Skinnskatteberg. There the strongly-luminous meteor projected on the snow-covered ground four or five bands of light with dark intervals, "without there being any object between the meteor and the earth to cast ${ }^{x}$ By Prof. Nordenskjöld. Abstract of two papers in Trants. of the GeoBy Prof. Nordenskjöld. Abstract of two papers in
logical Society of Stockholm, 878 , Nos, 45,46 , and 47 . a shadow," the shadow in this case having probably been caused by fragments of cloud in the neighbourhood of the meteor.

The diameter of the meteor, as calculated from a number of observations of apparent size, varied from 200 to 2,500 metres. Prof. Nordenskjöld conșiders it probable that the Vener meteor, in its path through the atmosphere, formed a luminous ball of 400 to 500 metres' diameter.

When the above-described phenomenon took place, the ground in the middle and north of Sweden was still covered with snow, a circumstance favourable for ascertaining whether any solid particles fell from the meteor in question in the form of meteoric dust to the surface of the earth. Prof. Nordenskjöld requested a student, Herr Svenonius, to proceed to the supposed place of fall, and to endeavour, both by his own researches and by inquiries of persons resident in the region, to discover any remains of the meteor. He travelled several times across the region, and employed a large number of people in searching on the ice on Lake Vener. The result was negative, with the exception that Herr Svenonius found on Lake Vener small quantities of a black or dark grey dust, of doubtful origin, which under the microscope appeared to consist of-

I. Small aggregates of cells derived from higher plants and isolated or coupled plant-cells.

2. A black colloid substance, which formed the main mass of the dust.

3. Inorganic particles of dust, which were isotropical, and could thereby be easily distinguished from grains of sand, whichs entered very sparingly into the mixture. The dust scarcely contained any particles that were capable of being attracted by the magnet, whereby it differed completely from the dust collected on the polar ice during the Swedish expedition of 1872-73. From the small quantity of material that conld be employed for analysis, no complete chemical examination of the inorganic constituents could be carried out. The principal constituents were silica, 38 per cent, oxide of iron, 34 per cent. alumina, 8 per cent. No trace of cobalt, nickel, or phosphorus could be discovered.

The dust was found in small quantity on the borders of the small pools, which, under the influerce of the spring rise of temperature, were formed everywhere on the ice of Lake Vener.

It is probable that this meteor mainly consisted partly of gaseous: substances, partly of carbon, so finely divided that it was com. pletely burned during the short path of the meteor in the atmo. sphere of our globe.

The second meteor was seen on April 29 at 8.37 P.M. Greenwich mean time, over the greater part of Sweden, from a point lying a little to the south-east of Gothenburg to Vittangi in: the extreme north. It was also seen over a great part of Finland, and at St. Petersburg and Dorpat. Accounts from no fewer than seventy-three different places are given. The meteor had, when first observed, the appearance of a large star. Its. size increased, however, at first slowly, afterwards rapidly, so that it at length gave out a light so bright that the country over which it passed was lighted up as if it had been full day. The light increased in brightness until the meteor exploded about haif way between Luleå and Pitea at a height of 35 kilometres. The time that elapsed between the first appearance of the meteor and its explosion did not exceed a minute and a half. The phenomenon, however, did not come to an end then. A part of the meteor appears, after the explosion, to have continued its course, and perhaps may have passed out of the atmosphere. Besides the usual line of sparks which generally marks the path of a meteor for some moments, there occurred in this case along a considerable part of the path a splendid light phenomenon of a red colour, which, however, was only observed in regions far re. moved from the place of explosion. This red appearance lasted from fifteen to thirty minutes. After it ceased the path of the meteor was still marked in the heavens for a long time (upwards of an hour) as a light band of cloud, which first assumed a zigzag form and then gradually disappeared. The whole phenomenon accordingly lasted nearly two hours, and it is probable that the meteor, or parts of it, both when it first appeared as a star and after the red light ceased, shone not with its ozen light but with light reftected from the sut?.

The statements as to the time during which the fre-ball itself was luminous in the atmosphere differ, varying from some few to ninety seconds. The latter, however, is the only one which has reference to the whole of the time during which the meteor was inmincus from its first appearance as a large star to its explosion. 
in the region of Lulea. The red light was visible at different places for periods varying from ten to thirty minutes, the light sireak of cloud from some minutes to seventy-five, the whole phenomenon being visible from ten to 105 minutes.

At places nearest to the locality of explosion and at some others there was seen only the intensely luminous fire-ball, not the red after-light, probably in part owing to the sky being cloudy, and in part also for the same reason as that which caused the dark central field in the case of the Stalldalen meteor.

The observations reported correspond so closely with the figures caiculated on the supposition that the explosion took place half way between Lulea and Nederkalix at a height of 35 kilometres above the surface of the earth, that this point of the meteor's path may be considered as determined with considerable accuracy.

All observers agree in this, that the red pillar of fire which immediately after the explosion was seen at Upsala, Stockholm, Fredrikshaman, St. Petersburg, \&ce., had at first the same direction as the meteor's spark-bestrewn path, but that the position of the fire-pillar towards the close of the phenomenon underwent change by its spreading out to a height in the atmosphere which in the north of the Gulf of Bothnia was about three times as great as that of the fire-ball proper.

The tangent of the meteor's path at the place of fall had an inclination to the horizon of about $25^{\circ}$. The radiation point was situated somewhere in the constellation Orion. The meteor appears to have been first seen at a height at which it was beyond the earth's shadow, and illuminated by the sun. At first it had the appearance of a bright star, but afterwards increased rapidly in diameter till its apparent size was equal to that of the sun or moon. From a comparison of numerous observation it appears that the meteor's luminous nucleus had a ciameter of 1,000 metres.

The Lulea meteor is interesting for the splendid light-phenomenon visible after its explosion, and particularly for the long time it remained in the atmosphere without much change of place.

This light began immediately before the meteor exploded in the xegion of Lulea, but it could not have been caused by combustible substances thrown off in consequence of the explosion, as in that case the red light ought to have spread itself from the place of explosion about equally in all directions, and afterwards have sunk down rapidly and gone out. Instead, this light was extended in the direction of the meteor's path, and it remained in the sky for more than an hour. An approximate idea of its size and height in the atmosphere is given by observations at Upsala and Fredrikshamn :-

\begin{tabular}{|c|c|c|}
\hline$(2)$ & $\begin{array}{l}\text { Breadth of the red } \\
\text { luminous pillar. } \\
\ldots \quad 6 \text { kilom. }\end{array}$ & $\begin{array}{l}\text { Approximate heigh } \\
\text { of the point. } \\
\text { I } 25 \text { kilom. }\end{array}$ \\
\hline Fredrikshamn & $\ldots \quad 12$, & 150 \\
\hline
\end{tabular}

The appearance of this light varied much. At some places it resembled a pillar of equal breadth ("like a beam "), at others it appeared as a red spot, from which a pillar of the same colour descended to the horizon but disappeared sooner; at others, again, luminous rings were observed. After the light itself dis appeared, its position in the sky was marked for a long time by numbers of "wool-like" clouds.

Several observers remark that the red fire-pillar in question, during the time that it remained visible in the sky, slowly as sumed a more vertical position, and then took the form of a 7 or a reversed S.

The Luleå meteor besides, like most other meteors, left behind it for some moments a white luminous streak of fire in that part of the sky through which it passed. This streak of fire clearly arose from constituent parts of the fireball proper which had been loosened by the resistance of the air, and remained behind.

The red light, on the other hand, appears to have had a different origin. It could not have consisted of small particles left behind in the uppermost strata of the atmosphere, for they would speedily have fallen down. The light rather appears to have originated from new combustible or luminous material which followed the nucleus of the meteor, and for the space of half an hour entered the atmosphere at nearly the same place. The Lulea meteor was thus a true cometoid.

It appears that the attraction of the earth and the retardation caused by the resistance of the air gave the path of the dust, causing the red light, a more parabolic form than that of the meteor's nucleus, for a number of observers state that the red pillar gradually raised itself from the slanting position of the path of the meteor towards the vertical line. The direction of the meteor's train, as in the case of true comets, did not lie quite in the path of the meteor. The foot of the luminous pillar was observed above Avasaxa at a height of about roo kilometres when the nucleus exploded north of Luleå. After the disappearance of the red light there remained white and woolly clouds, resembling light clouds illuminated by the sun. These may have arisen from parts of the meteor which were directly illuminated by the sun, and thus became visible when the stronger light, caused by direct combustion, ceased. On A pril 29 , in the latitude of Avasaxa, bodies at a greater height from the surface of the earth than ' 76 kilometres are beyond the shadow of the earth even at midnight.

The meteor's light was at first white, then for a long time of the same shade of red as the dawn, and near the close of the phenomenon again white. The light probably arose from the combustion of carbon and carburetted hydrogen, the products of combustion, steam, carbonic acid, \&c., absorbing part of the rays of light, and giving the nucleus a reddish tinge. Towards the close the gaseous envelope was dispersed, and the red colour ceased a long while before the meteor finally disappeared. Search was made for any meteorites or meteoric dust that might have fallen, but none were found, although stones were seen to fall to the ground "like rain" by two Lapp girls near Jock. mock, and a Lapp reindeer-herd on the mountain Sarvikobbo saw the "stone-swarm" in question disappear in the forest below him.

\section{SCIENTIFIC SERIALS}

Annalen der Physiz und Chemie, No, 6.-In view of the considerable discrepancy between observation and theory with regard to the propagation of electricity, Herr Lorenz has been led to make fresh experiments (here described). In one method the telephone was used; the other was a modification of Feddersen's jar-discharge method. Herr Lorenz shows that, in the case of iron telegraph lines, the magnetism of the iron must be considered. The electro-dynamic constant of unit length of an overland telegraph wire is expressed by $\mathrm{C}=2 \log . \frac{2 \hbar}{a}+2 \pi k$, where $\bar{h}$ denotes the height above the grould, a the radius of the wire, and $k$ the function of magnetisation. For unmagnetic wires, the latter member falls away. Applying the formula to Fizeau and Gounelle's experiments, and putting the function of magnetisation of the iron wire $=10$, we get the velocity 126000 $\mathrm{km}$., while that observed was IOI/10 $\mathrm{km}$. The difference i much less than by the ordinary reckoning, and may be attributed, the author thinks, to faults of insulation.-Studying the generation of the currents of a Gramme machine with regard to time and resistance, Herr Herwig finds, inter alia, that at the commencement a greater manifestation of force is obtained with greater resistances; but in later stages of development of the current, the force increases more for smaller resistances. The slow development of current with great resistances is shown by the fact that with $13 \% 4$ Siemens' units, the full force possible was not reached in four seconds.-Prof. Colley concludes from experiment, that the "polarisation of electrodes" in electrolytes is not to be attributed to dielectric polarisation of the latter, but deserves the name just given. It is not denied, however, that the dielectric polarisation may exist, being completely masked by the other.-Herr Settegaast makes some contribu. tions to quantitative spectral analysis; his paper treating (r) of distribution of a base between chromic acid and other acids (2) of quantitative mode of determination of nitric acid, and (3) of determination of phosphoric acid.-Among the remaining subjects handled, we note the angle of polarisation of fuchsin (Glan), application of the method of dimensions to proof of physical propositions (Neasen), and the heat-conduction of liquids with reference to currents arising from differences of temperature (Oberbeck).

THE Quarterly Fournal of Microscopical Science, July, contains : -Notes on some of the reticularian rhizopoda of the Challenger expedition, by H. B. Brady, F.R.S., with a plate. In this second memoir several new and most interesting forms are described and figured. The author mentions that he has failed to detect in fresh specimens of Dactylopora eruca, P. \& J., the structures figured by M. Munier-Chalmas, which figures happen to be reproduced in this number of the Journal, as part of the minutes of the Dublin Microscopical Club.-On the morphology of the vertebrate olfactory organ, by A. M. Marshall, M.A., with two piates.-On the brain of Blatta orientalis, by E. T. Newton, with two plates. - On the microphytes which have been found in the blood and their relation to disease, by Dr. T. R. Lewis, with 